\title{
Design and Analysis of a New Multiphase Polygonal-Winding Permanent-Magnet Brushless DC Machine
}

\author{
Yong Wang, K. T. Chau, Member, IEEE, Jinyun Gan, C. C. Chan, Fellow, IEEE, and J. Z. Jiang
}

\begin{abstract}
In this paper, a new multiphase polygonal-winding permanent-magnet brushless dc (PMBDC) machine is proposed and analyzed. The originality of the proposed machine lies on the multiphase polygonal-winding stator and the surface-inset permanent-magnet rotor. Because of its unique structure and operating principle, a circuit-field-torque coupled time stepping finite-element method is also employed for analysis. The designed machine is prototyped and the analysis is verified by experimentation.
\end{abstract}

Index Terms-Brushless dc machine, permanent-magnet machine, time-stepping finite-element method.

\section{INTRODUCTION}

$\mathbf{E}$ LECTRIC machines are one of the key technologies of electric vehicles (EVs), and aim to offer high efficiency, high power density, wide speed range, high controllability, and maintenance-free operation. The permanent-magnet brushless dc (PMBDC) machine inherently offers the advantages of high efficiency, high power density and maintenance-free operation. However, because of the uncontrollable permanent-magnet (PM) flux, it suffers from a short constant-power operating range. To solve this problem, the field-oriented flux-weakening control and the advanced conduction angle control were developed [1], [2]. Instead of using complicated control strategies, a machine topology with its flux specially regulated by two-phase stator currents was also proposed [3].

The purpose of this paper is to propose and analyze a new multiphase polygonal-winding PMBDC machine which incorporates a novel multiphase polygonal-winding stator and a unique surface-inset PM rotor. By electronically controlling the magnitude of the stator current flowing through the polygonal winding, the air-gap flux can be easily adjusted to achieve high-speed constant-power operation. Meanwhile, the surface-inset PM rotor can generate both the PM torque which is approximately proportional to the phase current (offering the characteristics of a conventional PMBDC machine), and the reluctance torque which is approximately proportional to the square of phase current (offering the characteristics of a brushed dc series machine). The uniqueness of this rotor is its PM pole width, which is about $2 / 5$ pole-pitch (different

Manuscript received February 10, 2002; revised April 28, 2002. This work was supported by the Hong Kong Research Grants Council under Project HKU 7035/01E.

Y. Wang, K. T. Chau, J. Gan, and C. C. Chan are with the Department of Electrical and Electronic Engineering, The University of Hong Kong, Hong Kong (e-mail: ywang@eee.hku.hk; ktchau@eee.hku.hk; jygan@eee.hku.hk; ccchan@eee.hku.hk).

J. Z. Jiang is with the School of Automation, Shanghai University, Shanghai, China (e-mail: jzhjiang@yc.shu.edu.cn).

Digital Object Identifier 10.1109/TMAG.2002.802128.

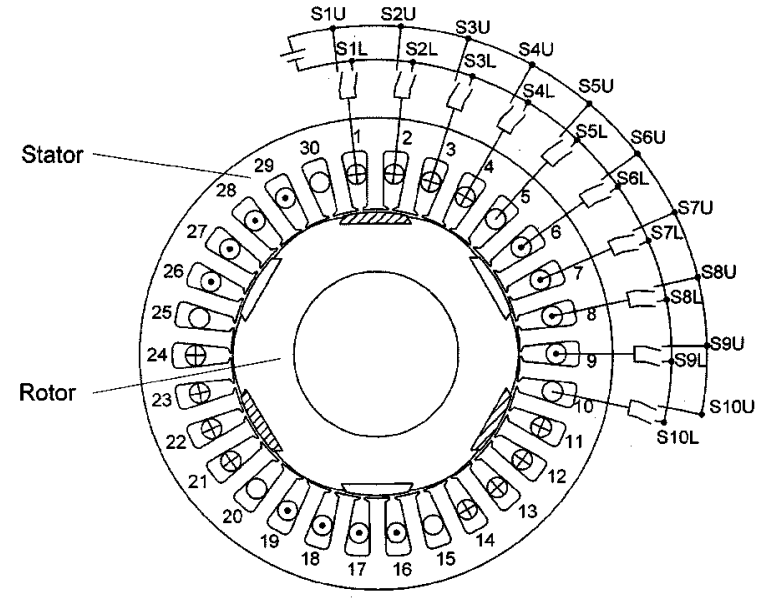

Fig. 1. Five-phase polygonal-winding PMBDC machine.

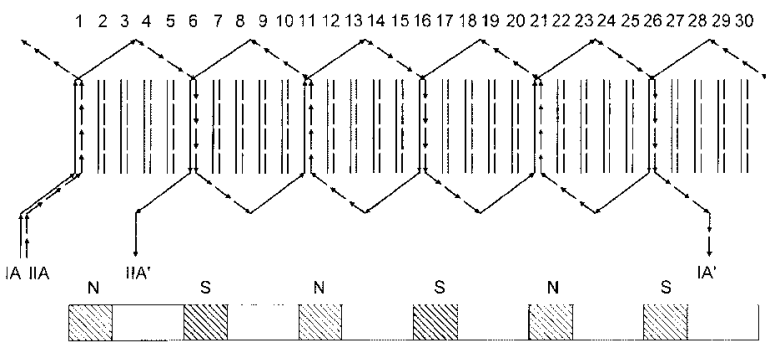

Fig. 2. Winding connection of phase A.

from $1 / 2$ pole-pitch of a conventional one [4]) and its eccentric core surface, thus offering lower PM material cost and lower armature reaction, respectively [3].

\section{MACHINE Design}

The proposed five-phase polygonal-winding PMBDC machine is shown in Fig. 1. This machine inherits the surface-inset PM rotor from our previous PMBDC machine [3], hence the merits of high power density and high starting torque; whereas its stator winding arrangement and connection are fundamentally different. With the use of a ten-leg inverter, the polygonal-winding connection becomes flexibly controllable, making this machine alike a brushed dc machine. Inevitably, the required number of power devices is doubled, which is acceptable for EV application because the machine performance is of much higher interest than the inverter cost for EVs.

Fig. 2 shows the winding connection of phase A, where the upper layer of slot 1 is connected to the lower layer of slot 6 


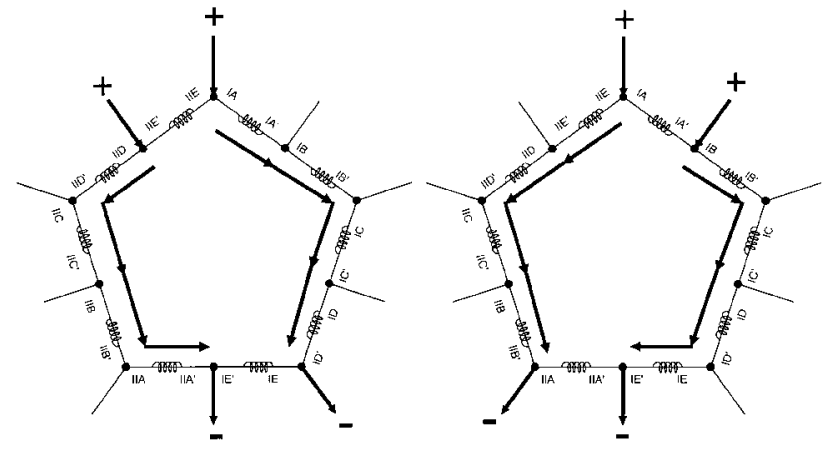

(a)

(b)
Fig. 3. Normal polygonal-winding excitations. (a) At $0^{\circ}$. (b) At $36^{\circ}$.

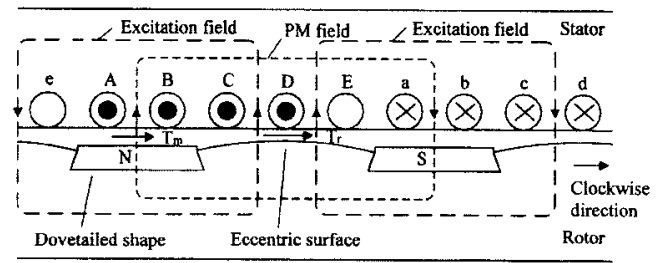

(a)

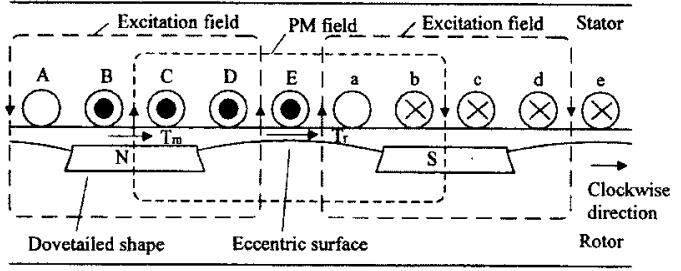

(b)

Fig. 4. Illustration of torque generation. (a) At $0^{\circ}$. (b) At $36^{\circ}$.

while the lower layer of slot 1 is connected to the upper layer of slot 26, and so on. Hence, there are two groups of phase A windings, namely IA-IA ${ }^{\prime}$ and IIA-IIA' . Similar connections are applied to other phases. Consequently, the windings of the same group are connected in series, and then the two groups are connected together to form a polygon as shown in Fig. 3.

\section{PRINCIPLE OF OPERATION}

Under normal operation, at any instant, there are four phases in the conducting state and one phase in the commutating state, so-called the 4/5-mode of operation. Each phase conducts for $144^{\circ}$ and commutates for $36^{\circ}$ within a half-cycle. When the rotor position is as shown in Fig. 1, the switches S1U, S5L, S10U, and S6L are on whereas all other switches are off, thus phases A-D are conducting while phase $\mathrm{E}$ is commutating as shown in Fig. 3(a). At this moment, phases A and B are under the PM pole, whereas phases $\mathrm{C}-\mathrm{E}$ are under the rotor core. The PM pole provides PM field for phases $\mathrm{A}$ and $\mathrm{B}$, hence generating a PM torque $\mathrm{T}_{m}$. Meanwhile, the currents in phases $\mathrm{A}$ and $\mathrm{B}$ provide excitation field to interact with the currents flowing in phases $\mathrm{C}$ and $\mathrm{D}$, hence generating an additional reluctance torque $\mathrm{T}_{r}$. Both torques are added up to cause rotation as visualized in Fig. 4(a). Notice that the currents in phases $C$ and $\mathrm{D}$ also provide excitation field to interact with the currents flowing in phases $\mathrm{A}$ and $\mathrm{B}$, hence creating an opposite reluctance torque; however, it is negligible because the PM material

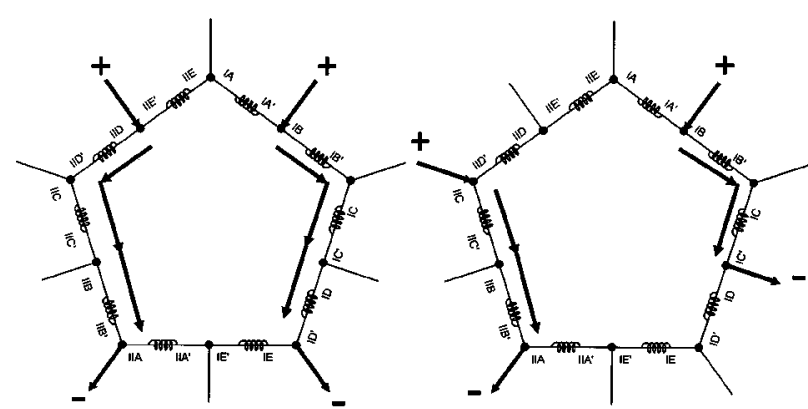

(a)

(b)

Fig. 5. Special polygonal-winding excitations. (a) 3/5-mode. (b) 2/5-mode.

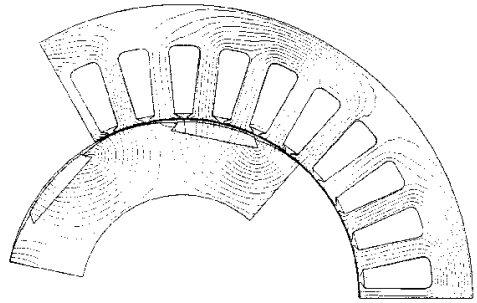

Fig. 6. Full-load flux distribution.

acts as a large airgap to suppress this excitation field. After $36^{\circ}$ rotation, as shown in Fig. 3(b), phases B-E become conducting while phase A becomes commutating. The resulting PM and reluctance torques continue the rotation as visualized in Fig. 4(b).

During high-speed constant-power operation, the proposed machine can easily offer the desired flux weakening by simply decreasing the magnitude of stator current (which is different from the phase control for conventional flux weakening). For this machine, the airgap flux and hence the back electromotive force (EMF) can be considered to be from two different sources-namely, the PM field and the excitation field. Although the PM field is uncontrollable, the excitation field (which is approximately proportional to the phase current) is easily controllable. By simply decreasing the magnitude of phase current, the excitation field is weakened and hence the corresponding back EMF component is proportionally reduced. Thus, another back EMF component due to the PM field can take up a larger portion which allows for a higher operating speed under the same PM flux. Therefore, the high-speed constant-power operating range of this machine can be significantly extended.

Increasingly, the proposed polygonal winding potentially allows the machine operating at other special modes of operation, namely the 3/5-mode (three phases conducting and two phases commutating) as shown in Fig. 5(a) or the 2/5-mode as shown in Fig. 5(b). This possible mode-changing operation can offer various torque-speed capabilities, and is promising to $\mathrm{EV}$ application.

\section{TIME-STEPPING FEM ANALYSIS}

Because of the unique structure and operating principle of the proposed machine, a two-dimensional (2-D) circuit-fieldtorque coupled time stepping FEM is adopted for analysis. Both the flux distribution and performance characteristics of the proposed machine are presented. Fig. 6 shows the full-load flux dis- 


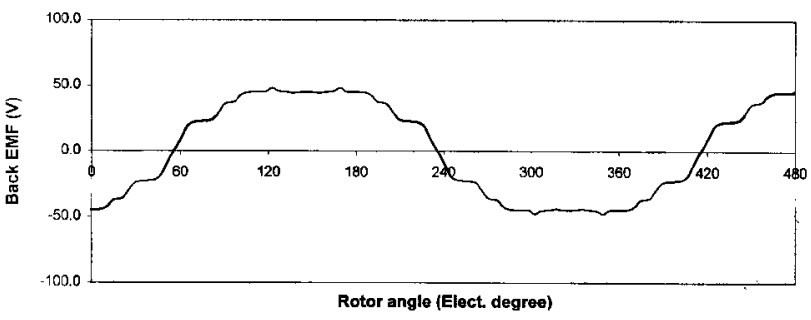

(a)

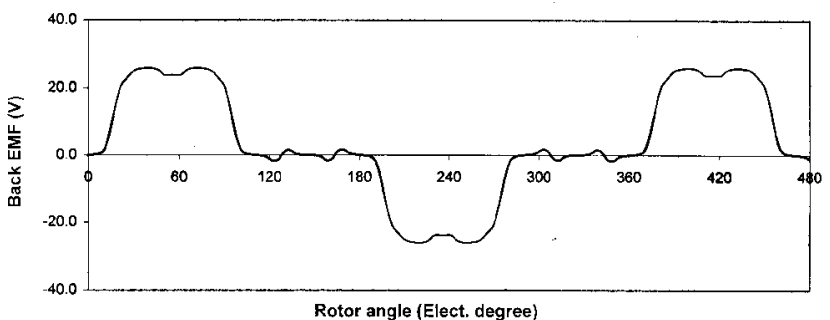

(b)

Fig. 7. Calculated back EMF waveforms. (a) Per group. (b) Per phase.

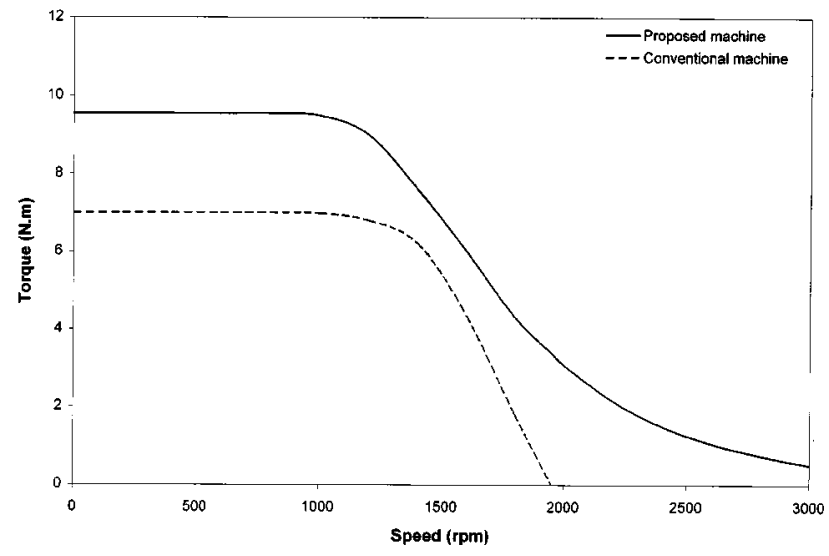

Fig. 8. Comparison of torque-speed capabilities.

tribution of the proposed machine. Then, as shown in Fig. 7, the corresponding no-load back EMF waveforms with respect to the rotor position are calculated under the base speed of $1000 \mathrm{r} / \mathrm{min}$. In order to illustrate the advantageous torque-speed capability of the proposed machine, it is compared with that of a conventional PMBDC machine, which has the same PM poles as well as current and voltage ratings. As shown in Fig. 8, the proposed machine exhibits a better torque-speed capability in terms of both maximum torque and speed range.

\section{VERIFICATION}

An 1-kW 96-V 1000-r/min prototype of the proposed machine is designed and built. The corresponding technical data is given in Table I. When the machine runs at the base speed of $1000 \mathrm{r} / \mathrm{min}$, the no-load back EMF waveforms are measured as shown in Fig. 9. It can be found that the measured waveforms closely agree with the calculated ones shown in Fig. 7. Hence, the validity of the calculated results using the circuitfield-torque coupled time-stepping FEM is verified.
TABLE I

MOTOR DATA

\begin{tabular}{ll}
\hline Rated power & $1 \mathrm{~kW}$ \\
Rated voltage & $96 \mathrm{~V}$ \\
Rated speed & $1000 \mathrm{rpm}$ \\
Rated phase current & $13.6 \mathrm{~A}$ \\
Stator & $180 \mathrm{~mm}$ \\
Outer diameter & $110 \mathrm{~mm}$ \\
Inner diameter & $60 \mathrm{~mm}$ \\
Stack length & 30 \\
Number of slots & Double layer \\
Winding type & 8 \\
Turns per coil & $0.072 \Omega$ \\
Resistance per phase $\left(75^{\circ} \mathrm{C}\right)$ & $109 \mathrm{~mm}$ \\
Rotor & $63 \mathrm{~mm}$ \\
Outer diameter & 6 \\
Inner diameter & $4.5 \mathrm{~mm}$ \\
Number of poles & $64 \mathrm{~mm}$ \\
Magnet height (maximum) & $1.10 \mathrm{~T}$ \\
Magnet length & Nd-Fe-B \\
Magnet remanence & \\
Magnet material & \\
\hline
\end{tabular}

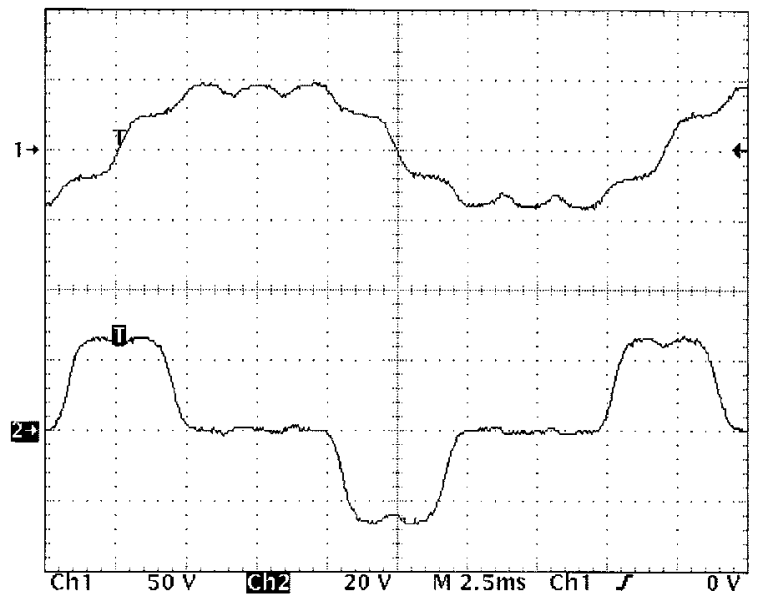

Fig. 9. Measured back EMF waveforms (50 V/div, $20 \mathrm{~V} /$ div, $2.5 \mathrm{~ms} /$ div).

\section{CONCLUSION}

A new multiphase polygonal-winding PMBDC machine has been proposed and analyzed. The keys are to use the polygonal-winding stator for flux weakening or possible mode-changing operation, and to employ the surface-inset PM rotor for producing an additional reluctance torque, hence offering a better torque-speed capability. Also, a circuit-field-torque coupled time stepping FEM has been adopted for analysis. The machine has been prototyped and tested for verification.

\section{REFERENCES}

[1] L. Xu, L. Ye, L. Zhen, and A. El-Antably, "A new design concept of permanent magnet machine for flux weakening operation," IEEE Trans. Industry Applicat., vol. 31, pp. 373-376, Mar.-Apr. 1995.

[2] C. C. Chan, K. T. Chau, J. Z. Jiang, W. Xia, M. Zhu, and R. Zhang, "Novel permanent magnet motor drives for electric vehicles," IEEE Trans. Indust. Electron., vol. 43, pp. 331-339, Apr. 1996.

[3] J. Y. Gan, K. T. Chau, C. C. Chan, and J. Z. Jiang, "A new surfaceinset permanent-magnet brushless DC motor drive for electric vehicles," IEEE Trans. Magn., vol. 36, pp. 3810-3818, Sept. 2000.

[4] Z. Q. Zhu, D. Howe, and Z. P. Xia, "Prediction of open-circuit airgap field distribution in brushless machines having an inset permanent magnet rotor topology," IEEE Trans. Magn., vol. 30, pp. 98-107, Jan. 1994. 